\title{
Microtuber formation in potato callus
}

\author{
Seyedardalan Ashrafzadeh, David W.M. Leung* \\ School of Biological Sciences, University of Canterbury, Private Bag 4800, Christchurch 8140, \\ New Zealand
}

*Corresponding author, e-mail: david.leung@canterbury.ac.nz

Received 22 May 2014

Accepted 1 Feb 2015

\begin{abstract}
Potato callus has been shown to be capable of de novo organized development including shoot and root formation. A surprising finding in a study of potato (Solanum tuberosum cv. Iwa) callus culture initiated from leaf explants on a medium supplemented with auxin and cytokinin is reported here. Five weeks after callus formation, a low frequency (about 10\%) of the callus cultures had formed microtubers. The microtubers initially appeared to be light green and some were elongated. One week later the microtubers had lost much of the green appearance and were full of hairs on the side and with many scattered dark brown spots on the top view. Histological analysis showed that a microtuber was connected with the callus and not with the leaf explant as the callus typically lacked the internal organization of a leaf. This is the first report of the occurrence of microtubers in potato callus cultures.
\end{abstract}

KEYWORDS: histology, leaf explants, plant regeneration, tuberization

\section{INTRODUCTION}

The importance of potato (Solanum tuberosum L.) is linked to its ability to form nutrient-rich tubers which are the third most consumed food globally, just behind wheat and rice ${ }^{1}$. Potato tuberization has been a subject of extensive scientific investigations in the past half a century or so. In potato plants grown in the field, tubers develop underground from modified lateral shoots or stolons in response to favourable environmental conditions. Various experimental systems have also been shown to form microtubers. These include stem cuttings each consisting of a stem segment with a single leaf and an axillary bud meristem inserted in soil ${ }^{2}$, in vitro culturing of single-nodes without leaves ${ }^{3}$ and the shoots developed from the axillary buds of the micropropagated potato plantlets ${ }^{4}$. All these involve simplifications or minimizations of the intact tuberizing potato plant and rely on the cells of the lateral shoots or axillary bud meristems in the different experimental systems to form microtubers. Whether it is the intact plant grown in the field or one of these experimental systems, the tuberization process is accompanied by morphological and anatomical changes in the differentiated cells at the subapical region of the stolon or lateral shoot ${ }^{5}$.

Potato callus is an unorganised tissue formed following de-differentiation of cells derived from, for example, excised potato leaf ${ }^{6}$, internodal ${ }^{7}$ or tuber segments ${ }^{8}$ under plant tissue culture conditions.
Plant regeneration via de novo organogenesis ${ }^{7-10}$ or somatic embryogenesis ${ }^{6}$ in potato callus has been shown. In our unpublished observations on potato callus cultures initiated from leaf explants, unexpectedly microtuber development was found. Here, the objective is to be able to confirm this new finding as well as to perform histological analysis to determine whether the microtubers developed directly from the explant or indirectly from callus cells. This is the first report showing that microtubers could arise from potato callus and opens a new research area for probing the totipotency of plant tissue culture.

\section{MATERIALS AND METHODS}

Fully-expanded leaves (about $0.5 \times 0.5 \mathrm{~cm}$ ) were excised from 4- to 6-week-old plantlets of potato (S. tuberosum L. cv. Iwa) micropropagated as described previously ${ }^{11}$ and were cultured in plastic Petri dishes $(9 \mathrm{~cm}$ in diameter) containing half-strength basal Murashige and Skoog (MS) medium $^{12}$ supplemented with $3 \%(\mathrm{w} / \mathrm{v})$ sucrose, $4.43 \mu \mathrm{M}$ 6-benzyladenine (BA) and $5.37 \mu \mathrm{M}$ 1-naphthaleneacetic acid (NAA). All the media were adjusted to $\mathrm{pH} 5.8$ with $1 \mathrm{~N} \mathrm{KOH}$ or $1 \mathrm{~N} \mathrm{HCl}$ and $0.8 \%(\mathrm{w} / \mathrm{v})$ agar was added before the media were autoclaved at $121^{\circ} \mathrm{C}, 15 \mathrm{psi}$ for $15 \mathrm{~min}$. Five leaf explants were placed into each Petri dish and each treatment consisted of eight replicates. After placing leaf explants (with lower leaf surface in contact with the medium) on the surface of the medium in the 

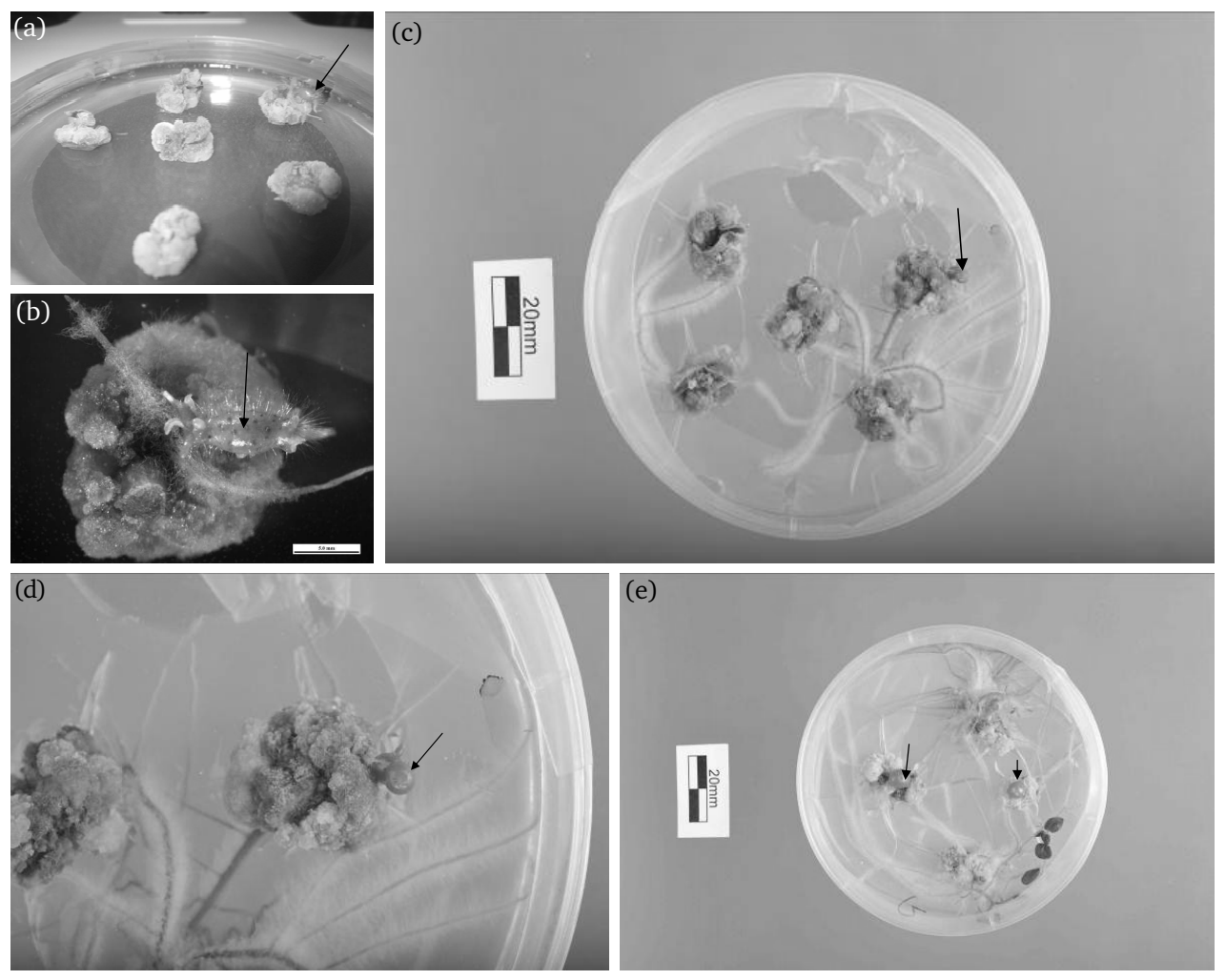

Fig. 1 Microtuber formation in leaf-derived potato callus cultures. The microtubers formed are indicated by the arrows. (a) Callus was initiated on a culture medium supplemented with $4.43 \mu \mathrm{M}$ BA and 5.37 $\mu \mathrm{M}$ NAA under continuous lighting. The photo was taken after 5 weeks from the start of culturing leaf explants excised from micropropagated potato plantlets cv Iwa. (b) Appearance of the callus/leaf explant with the microtuber shown in (a) two weeks later. (c-e) Examples of appearance of microtubers in potato leaf callus cultures from independent repeat experiments after six weeks from start of culturing leaf explants.

Petri dishes, strips of parafilm were used to seal around the Petri dishes. The cultures were regularly observed under a stereomicroscope mounted with a digital camera (MZ10 F, Leica, Singapore). The plantlets and callus were cultured in a growth room at $21 \pm 1{ }^{\circ} \mathrm{C}$ with continuous lighting.

For histological analysis, at least ten whole leaf explants together with microtubers and calli were fixed in $30 \mathrm{ml}$ of FAA (formalin-ethanol-acetic acid, 20:70:10) for about a month. They were dehydrated in an ethanol series and then embedded in paraplast wax. Longitudinal sections of $7 \mu \mathrm{m}$ through the microtubers and the region to which the microtubers were attached were cut before being mounted on microscope glass slides with Haupt's adhesive. Then the sections were de-waxed, stained in Mayer's double-strength haemalin and eosin, dehydrated, cleared and mounted in Eukitt. The sections were left to dry at the air for at least two days before observation under a light microscope (Axio Imager. M1, Carl Zeiss, Germany).

\section{RESULTS AND DISCUSSION}

The potato plantlets (S. tuberosum cv. Iwa) used in the present study were subcultured regularly every 6-8 weeks over several years from stock plants that were also used in a previous study on microtuber induction from the axillary buds of the plantlets under aseptic conditions ${ }^{11}$. In our laboratory, we have been initiating callus cultures from the explants of these micropropagated plantlets on agarsolidified half-strength MS basal media ${ }^{12}$ supplemented with $3 \%$ sucrose and different combinations of BA and NAA. The callus cultures were intended for somaclonal variation studies. Of initial interest was the callus on the medium supplemented with $4.43 \mu \mathrm{M}$ BA and 5.37 $\mu \mathrm{M}$ NAA, the compact callus appeared green or light creamy yellow and had grown to cover much of the periphery and surface of the leaf explants after three to four weeks of culturing (Fig. 1a). Surprisingly, one to two weeks later a microtuber was found in one of the callus (Fig. 1a). 

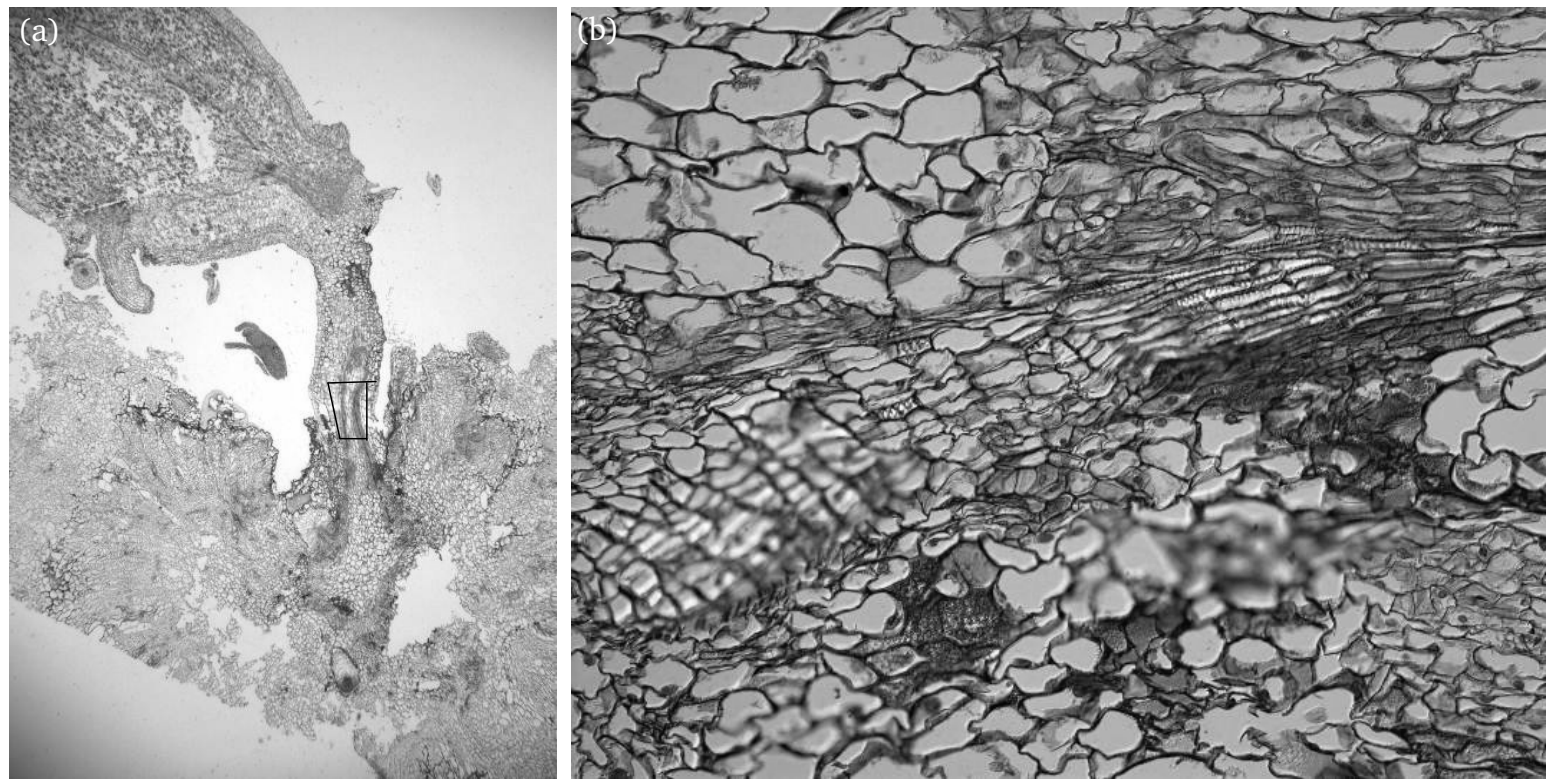

Fig. 2 Histological analysis of potato microtuberization from leaf-derived callus. (a) Light microscopic image of a longitudinal section through a microtuber (shown in Fig. 1b) connected to a mass of leaf-derived callus; $1.25 \times$ magnification. (b) A close-up view of the inset in (a) showing the organization of vascular tissues in the region connecting the microtuber to the callus; $20 \times$ magnification.

It appeared to be light green and elongated. One week later this microtuber had lost much of the green appearance and appeared to be full of hairs on the side and with many scattered dark brown spots on the top view (Fig. 1b). The formation of secondary microtubers was also evident. The microtuber was reactive to Lugo's solution (I/KI) indicating the presence of starch (result not shown). There were a few long roots formed in the callus cultures. As far as we are aware of, this was the first time that a microtuber was formed from a callus culture. Repeat experiments showed that about 10\% of the callus formed microtubers (Fig. 1c-e). About five to six weeks from start of culturing the leaf explants, green and round microtubers were formed (Fig. 1c-e). The microtubers also turned brown in another week or so. Inspection of callus cultures on other different media did not find microtuber formation (results not shown).

The possibility that the microtubers might be formed directly from the differentiated cells of the leaf explants rather than from the callus was investigated. The sections from the region connecting a microtuber to the callus/leaf explants was taken and prepared for observations under a light microscope. The histological analysis clearly revealed that a microtuber was connected with the callus (Fig. 2a) and not with the leaf explant as the callus lacked the typical internal organization of a leaf. In the region of the callus connecting with the microtuber, there were well formed vascular tissues: xylem vessels with apparent spirals of cell wall thickening and other unorganized callus cells of heterogenous appearances (Fig. 2b). Histological analysis of the similar region connecting another microtuber to the callus/leaf explant initiated in a repeat experiment support that the microtubers did not develop directly from the leaf explants but from callus (results not shown). Although the ontogeny of microtuber initiation from the callus derived from the leaf explant remains to be fully established at present, the results obtained here support that microtubers could be formed de novo from potato callus.

A survey of the literature about regulation of tuberization in field-grown potato plants has revealed that many environmental conditions including short photoperiods are known to be favourable for tuberization ${ }^{13}$. Under in vitro conditions, microtuberization could be initiated in total darkness ${ }^{14}$. It has also been shown that tuberization in plantlets or in the single node experimental system in vitro depends on an interplay of the composition of the culture medium and culture conditions ${ }^{15,16}$. In particular, high sucrose concentrations (for example, $8 \%, \mathrm{w} / \mathrm{v}$ ) and plant growth regulators such as cytokinin or anti-gibberellins are known to be favourable for 
tuberization in vitro ${ }^{17-19}$. Compared with these and other related studies in the literature, the culture medium and conditions used in the present study would not be expected to be inductive or permissive for tuberization. In contrast, the significant differences here were that (a) callus cells derived from the leaves of potato plantlets cultured in an extended period on a callus induction medium supplemented with $4.43 \mu \mathrm{M}$ BA and 5.37 $\mu \mathrm{M}$ NAA in sealed Petri dishes under continuous lighting appeared to be involved, and (b) a tuber organogenic pathway is induced from these callus cells. Further investigations into the critical factors such as plant hormones ${ }^{20,21}$, exogenous carbohydrate supply, and environmental conditions that might be involved in the regulation of tuber organogenesis in potato callus seem worthwhile.

Acknowledgements: We are grateful for the generous technical support in the Microscope Unit of School of Biological Sciences, University of Canterbury.

\section{REFERENCES}

1. Navarro C, Abelenda JA, Cruz-Oró E, Cuéllar CA, Tamaki S, Silva J, Shimamoto K, Prat S (2011) Control of flowering and storage organ formation in potato by Flowering Locus T. Nature 478, 119-23.

2. Duncan DA, Ewing EE (1984) Initial anatomical changes associated with tuber formation on single node potato (Solanum tuberosum) cuttings. Ann Bot 53, 607-10.

3. Xu X, Vreugdenhil D, van Lammeren AAM (1998) Cell division and cell enlargement during potato tuber formation. $J$ Exp Bot 49, 573-82.

4. Dhital SP, Lim HT (2012) Microtuberization of potato (Solanum tuberosum L.) as influenced by supplementary nutrients, plant growth regulators, and in vitro culture conditions. Potato Res 55, 97-108.

5. Aksenova NP, Konstantinova TN, Golyanovskaya SA, Sergeeva LI, Romanov GA (2012) Hormonal regulation of tuber formation in potato plants. Russ J Plant Physiol 59, 451-66.

6. JayaSree T, Pavan U, Ramesh M, Rao AV, Reddy KJM, Sadanandam A (2001) Somatic embryogenesis from leaf cultures of potato. Plant Cell Tissue Organ Cult 64, 13-7.

7. Pal AK, Acharya K, Ahuja PS (2012) Endogenous auxin level is a critical determinant for in vitro adventitious shoot regeneration in potato (Solanum tuberosum L.). J Plant Biochem Biotechnol 21, 205-12.

8. Abd Elaleem KG, Modawi RS, Khalafalla MM (2009) Effect of plant growth regulators on callus induction and plant regeneration in tuber segment culture of potato (Solanum tuberosum L.) cultivar Diamant. Afr J Biotechnol 8, 2529-34.
9. Yee S, Stevens B, Coleman S, Seabrook JEA, Li XQ (2001) High-efficiency regeneration in vitro from potato petioles with intact leaflets. Am J Potato Res 78, 151-7.

10. Dokhaniyeh AY, Kohnehrouz BB, Mousavi A, Gholizadeh A, Khalighi A (2011) Rapid and high efficiency regeneration from potato (Solanum tuberosum L.) using thidiazuron as cytokinin source. $J$ Food Agr Environ 9, 613-7.

11. Yoon KS, Leung DWM (2004) Relative importance of maltose and sucrose supplied during a 2-step microtuberization process. Acta Physiol Plant 26, 47-52.

12. Murashige T, Skoog F (1962) A revised medium for rapid growth and bioassays with tobacco tissue cultures. Physiol Plant 15, 473-97.

13. Ewing EE, Struik PC (1992) Tuber formation in potato: induction, initiation, and growth. In: Janick J (ed) Horticultural Reviews, Vol. 14, Wiley, pp 89-198.

14. Lawerence CH, Barker WG (1963) A study of tuberization in the potato, Solanum tuberosum. Am Potato $J$ 40, 349-56.

15. Hussey G, Stacey NJ (1984) Factors affecting the formation of in vitro tubers of potato (Solanum tuberosum L.). Ann Bot 53, 565-78.

16. Gopal J, Minocha JL, Dhaliwal HS (1998) Microtuberization in potato (Solanum tuberosum L.). Plant Cell Rep 17, 794-8.

17. Khuri S, Moorby J (1995) Investigations into the role of sucrose in potato cv. Estima microtuber production in vitro. Ann Bot 75, 295-303.

18. Harmey MA, Crowley MP, Clinch PEM (1966) The effect of growth regulators on tuberisation of cultured stem pieces of Solanum tuberosum. Eur Potato $J \mathbf{9}$, 146-51.

19. Ebadi M, Iranbakhsh A (2011) The induction and growth of potato (Solanum tuberosum L.) microtubers (santé cultivar) in response to the different concentrations of 6-benzylaminopurine and sucrose. Afr J Biotechnol 10, 10626-35.

20. Raspor M, Motyka V, Zizkova E, Dobrev PI, Travnickova A, Zdravkovic-Korac S, Simonovic A, Ninkovic S, Dragicevic IC (2012) Cytokinin profiles of AtCKX2overexpressing potato plants and the impact of altered cytokinin homeostasis on tuberization in vitro. J Plant Growth Regul 31, 460-70.

21. Roumeliotis E, Kloosterman B, Oortwijn M, Kohlen W, Bouwmeester HJ, Visser RGF, Bachem CWB (2012) The effects of auxin and strigolactones on tuber initiation and stolon architecture in potato. $J$ Exp Bot 63, 4539-48. 